\title{
Situation, Problems and Countermeasures of Leisure Industry
}

\section{Development}

\author{
Haiyan Zhan ${ }^{1}$ \\ ${ }^{1}$ Shaanxi Institute of International Trade \& Commerce, Xian Yang, Shaanxi, 712046
}

KEYWORDS: Situation; Problems; Countermeasures; Leisure Industry Development

\begin{abstract}
With the social and economic development, leisure has become a consumer phenomenon and leisure industry has become the focus of scholars at home and abroad. This paper reviews the status quo at home and abroad Development of leisure industry, the development of leisure industry, leisure industry pointed out problems in the development, strategy and made a number of recommendations to promote the development of the leisure industry.
\end{abstract}

\section{Introduction}

Leisure has become an important characteristic of the times and people's daily life is an integral and important part. Leisure as a new social and cultural phenomenon, will structure the daily life have a profound impact on social structures and human behavior. At present, China has upgraded the consumer from subsistence to a well-off type object of consumption from food and clothing problem of subsistence will shift to improve the quality of life of the well-off subsistence based. With the social and economic development, leisure has become a consumer phenomenon. Development of the leisure industry has important theoretical and practical significance.

\section{The Leisure and Leisure Industry}

In the next 20 years or longer, the leisure will become an important part of human life, to meet people of leisure, spiritual and cultural needs as the main content of the leisure industry will be dominated by the global economic life. The so-called leisure industry refers to people's leisure life, leisure behavior, leisure needs (physical, mental) closely related fields, especially in the tourism, entertainment, service and cultural industries as the leading industrial and economic form system, generally including national parks, museums, sports, film and television, transportation, travel agencies, restaurants, community services, and thus the associated industries. From our present situation, the leisure industry should at least include leisure and entertainment industry, leisure tourism, leisure and health, leisure education, leisure clothing, leisure catering, leisure and culture industry and so on. In these industries, including not only provide services to consumers in the tertiary industry, but also to provide consumers with manufacturing leisure products, leisure facilities, leisure facilities and other conditions, processing industry, construction and other industries. Seen in this light, the leisure industry is a comprehensive industry can absorb large numbers of workers across the secondary and tertiary industries, it will become the new economic growth point of the community.

\section{The Development Status of Leisure Industry}


Since the reform and opening up, China residents disposable income and leisure basic synchronized growth in the consumer area from the completion of the desire to meet the physical, material desire to spiritual desire change. 1980 is the desire of residents to meet the physical period. Wherein the easiest people to food, clothing and basic subsistence pursuit met, gradually canceled some supply ticket out from the shadow of a shortage economy, the increase in the number of goods, color, variety. 1993--2005 years Yes domestic residents to meet the desire for material period. Wherein people focus on the pursuit of self-designed, self-realization, and its importance to explore the cultural connotation of basic necessities, consumption of cultural products become fashionable, people not only need to have a rich spiritual and cultural products, they need to spend leisure time, to experience these products .

Researchers developed Western countries are already well underway for leisure, many scholars the author discusses the relationship between "Work" and "free", and recognized the "leisure" value, and the more general leisure education, so as to form a more systematic theoretical system. But in China, has long been the term "casual" full of prejudice. First of all, when it comes to "free", it is naturally linked to the "much ado about nothing" and so on. This old ideas and the deviation of casual knowledge directly restricts the development of China's leisure industry. Secondly, our traditional concept of consumption frugal, more emphasis on "Mr. postpartum consumption" or "re-production of light consumption" these consumer attitudes directly restricts the development of the leisure industry.

Unbalanced development of the leisure industry, as a whole, restricted the development of China's leisure and industry, mainly in the following three aspects: First, the overall supply and demand of leisure imbalance. The present main leisure supply mainly in food, travel, play, etc., supplied or vulgar level is relatively low, the relative lack of supply the spiritual needs of the relatively high level of cultural products, leisure and education supply and so on. This imbalance is a direct result of supply and leisure ordinarily resident leisure consumption deformity. Leisure Consumption true scientific sense should be focused on fun, leisure behavior change in people's leisure, it advocates the consumption rationalization and adaptability, a sense of human freedom, a sense of calm; the pursuit of experience, experience, consciousness and beliefs. And the current supply cannot effectively provide the necessary leisure products for the leisure consumption, thus further affecting the healthy development of the leisure industry. Second, the development of leisure industry structure imbalance. From the current structure and layout of the leisure industry, the tourism industry thriving, and cultural industries, sports industry, entertainment and other tourism industry is relatively lagging behind.

Leisure industry is a complex social system project and its development requires various related fields or links of coordination and cooperation. However, the current situation of our country, our country's social support system is relatively backward. Since 1995, China began to implement five-day working week, introduced in 1999, "the Spring Festival, May Day, eleven" since three long holiday system, China's tourism industry is gradually warming up, triggering a large-scale development of the leisure industry, but As with the development of the leisure industry supporting projects not yet formed, which also produced a number of unsatisfactory issues. From the data published by the relevant state departments, the country in recent years, the prevalence of traffic overcrowding, inadequate supply of various recreational infrastructure and other issues directly restricts the development of China's leisure industry, limiting the consumption of leisure.

\section{Main Problems of the Leisure Industry Development Process}


Our country has always been a country, has its positive side, but also has its negative side. Development and enjoyment of contempt, contempt service economy, "first production, post-consumer" concept deeply rooted consciousness leisure, leisure activities form a single, monotonous, think casual just watch TV, string pro and friends, eat, drink, goods tea, chat, shopping, shopping, etc., a lot of people to sleep, play cards, watch TV as the main way of leisure, with the rest in place of recreation. So that the development of the leisure industry and the lack of strong power demand.

Leisure infrastructure is to carry out the material basis for the development of leisure activities and leisure industry. Carry out leisure activities require public leisure space, space, transport, accommodation and dining options. In recent years, these recreational infrastructures are growing rapidly, but still cannot meet the demand for people to relax. Open space, green areas and roads are the main elements of urban public leisure venues. Although these elements are on the rise, but the space for public recreation and leisure is not a lot, some of the city's main square, large lawn to enhance the taste of the city, but not necessarily good public recreation space, lack of chairs small stool, sports activities equipment scarce public leisure space is a common problem. In absolute terms, China's sports venues already has a considerable scale, but relative number, the sports venues per capita area of less than one square meter. Although tourism infrastructure, transportation and communication facilities, network infrastructure and other construction has made great achievements, but still cannot meet the demand for people to relax.

Performance in the blind selection of leisure destinations, your favorite suit, people where to go, they would go along, do not look only to watch the doorway; fly when traveling, exhausted, just be satisfied with sightseeing, but did not go to leisure. At the same time, protection of consumer rights awareness is not strong, the lack of their rights and obligations of correct understanding, do not know how to use the law to protect their rights when their rights suffers loss, do not know how to take timely measures to minimize the loss has not occurred.

Leisure industry is a mutually supporting large-scale system and the need to support all aspects of society, therefore, need to build a large social support system, involving theoretical research, institution building, policies and regulations, social security, social security, social insurance, currency distribution, information exchange and involving many departments and units. Only all aspects of mutual cooperation, work together is possible to build leisure consumption of social support systems. In recent years, social support system construction of leisure consumption has made great achievements, but the development of leisure activities with respect to large-scale development and leisure industry, the social support system construction of leisure consumption is lagging behind. Far behind the actual theoretical research, the lack of appropriate systems, policies and regulations are incomplete, poor information and leisure, and recreation and leisure industry-related social security, social security and social insurance, etc., are to be strengthened construction.

\section{The Development Countermeasures of Chinese Leisure Industry}

Early 1980s, Yu Guangyuan, deputy director of the State Science Commission collected data show that, at the time, about the administration's nearly one hundred countries, are associated with the leisure sector and directly under the leadership of the world. This shows that the leisure industry in many countries at least at that time had become the official national industry. Especially the United States, the leisure industry already has hundreds of years of development history, has formed a set of sound scientific management system, therefore, it is necessary to introduce its advanced management ideas and technology for China's leisure industry services. 
First, focus on the development of urban leisure belt loops, small urban and rural areas should be the city as the basis, with secondary focus on the development of their own advantages and leisure industry. For example, the first industry to extend the tertiary industry, to form a tourism, entertainment, service and cultural industries as the leading industrial system, promote the further development of the banking, insurance, environmental protection industry, promote the adjustment of industrial structure, making casual industry to absorb the increasing proportion of the labor force. For example, the combination of returning farmland to forest and agricultural structure adjustment of agriculture, can develop leisure agriculture, the construction of public farm, farm tourism, agriculture park, farm education, leisure farms, carry folk tourism, mountaineering outdoor activities, tourism, visits, recreation, learning, wellness organically, nurturing the human spirit and to meet the material comforts of new agricultural industries.

As the government plans to guide development of the industry, must develop a set of policies and regulations to clarify the direction for the development of the leisure industry and target clearly defined industry-wide leisure industry, the role and status through policies, regulations, and guidance toward the leisure industry has conducive to political stability, economic prosperity, social progress and direction. Profitability is narrow, but the public loved culture and entertainment facilities (such as libraries, museums, cultural plaza, community room, etc.), the government should increase support for the implementation of financial support for the tourism industry, tariff reduction, long-term low-interest loans, credit guarantees, and actively provide preferential treatment and other measures. Second, adjusting the vacation time, holiday system reform, promote leisure consumption. Adjust the vacation time the implementation of the timeshare industry in order to avoid people due to the leisure time is too concentrated caused by the "bottleneck" phenomenon.

\section{Conclusion}

Leisure as a new social and cultural phenomenon, will structure the daily life have a profound impact on social structures and human behavior. At present, China has upgraded the consumer from subsistence to a well-off type and object of consumption from food and clothing problem of subsistence will shift to improve the quality of life of the well-off subsistence based. With the social and economic development, leisure has become a consumer phenomenon. Development of the leisure industry has important theoretical and practical significance.

\section{Acknowledgements}

Project: 2015 Shaanxi Provincial Science and Technology Department project "New West Ham Leisure Industry Development and Innovation Model".

Project NO. 2015KRM159

\section{Reference:}

[1] Riesman D, Glazer N, Denney R. The Lonely Crowd: A Study of the Changing American Character [M].New Haven: Yale University Press, 1977:66.

[2] Sebastien de Grazia. Of time, Work and Leisure [M]. New York: The Free Press, 1962.

[3] Pieper J. Leisure: The Basis of Culture [M].Random House, Inc.1963:20.

[4] Bell D. The Coming of Post-industrial Society [M].New York: Basic Books, Inc., 1973:126. 